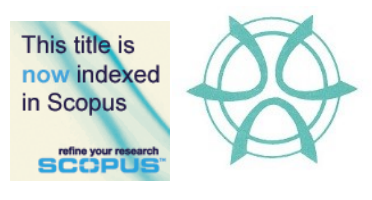

PLANNING MALAYSIA:

Journal of the Malaysian Institute of Planners

VOLUME 19 ISSUE 5 (2021), Page 169 - 179

\title{
THE EVALUATION OF PEDESTRIAN FACILITIES ON HAJJ CROWD BETWEEN $A R A F A T$ AND MUZDALIFAH PEDESTRIAN STREET
}

\author{
Sadeq Kadi', Alias Abdullah ${ }^{2}$, Syahriah Bachok ${ }^{3}$ \\ ${ }^{1,2,3}$ Faculty of Architecture and Environmental Design \\ UNIVERSITI ISLAM ANTARABANGSA MALAYSIA
}

\begin{abstract}
Makkah is the holy city of Muslims which is located in the southwest of Saudi Arabia. It is the being visited by pilgrims from all nationalities every year for the annual Islamic Pilgrimage (Hajj). Hajj is the fifth pillar of Islam which is the largest annual religious pilgrimage event in the world. The Hajj management authority specifies that the current pilgrimage's performance is challenging due to the increase of pilgrims every year. Pedestrian conflicts and uncomfortable walking environment are the crucial issues that have been identified, which are due to insufficient pedestrian facilities. Hence, this paper presents the pedestrian facilities assessment between Arafat to Muzdalifah road. The objectives of the study are to determine the available pedestrian facilities for pilgrimage from Arafat to Muzdalifah, and to suggest the suitable solution for pedestrian facilities in every 5 minutes walks. Meanwhile, qualitative methods of site inventory and observation were applied to gather the related data on the selected study area. Possible pedestrian facilities design is suggested for the purpose of future Hajj improvement.
\end{abstract}

Keywords: Pilgrims, Hajj, crowd, pedestrian facilities

\footnotetext{
${ }^{1}$ Sadeq Kadi. Email: Sadeq_kadi@hotmail.com
} 
Sadeq Kadi, Alias Abdullah, Syahriah Bachok

The Evaluation of Pedestrian Facilities on Hajj Crowd Between Arafat and Muzdalifah Pedestrian Street

\section{INTRODUCTION}

The meaning of Hajj (Meaning of Hajj), a program of movement from Arafat to Muzdalifa

The annual Islamic Pilgrimage (Hajj) is a unique religious gathering for millions of Muslims worldwide to be at one place (city of Makkah, Saudi Arabia) within specific days every year. Generally, Hajj is one of the five pillars of Islam, and it is a set of worship act to be performed in and around Makkah at least once of a Muslim's lifetime who satisfies a particular condition. Felemban et.al (2020), stated that Hajj is the massive gathering of Muslim events with around 3 million pilgrims visit Makkah every year. The Hajj pilgrimage consists of several religious rituals with complex movements. Moreover, the journey of Hajj usually completes over five days, and Makkah has hosted the annual pilgrimage for the last 14 centuries. According to the current statistics by the General Authority for Statistics in Kingdom of Saudi Arabia (GASTAT), the pilgrims number are expected to increase every year (Alabdulkarim et al., 2016) .

\section{Understanding crowd management in the context of $\mathrm{Hajj}$}

In the normal condition of Hajj gathering, the massive pilgrims crowd had led to uncomfortable environment and uncompromised safety during the pilgrimages (Alabdulkarim et al., 2016). Crowd presence had reduced the physical bubble space of an individual and resource struggling (Gifford.2007). Pilgrims' behaviour particularly the changes of body sway had cause repetitive crowding disasters (Alnabulsi \& Drury, 2014). Kingshott (2014) specified that the crowd behaviour is vary depending on social, religious, emotional, cultural composition and intentions. Handling huge pilgrim crowd's movement in the holy city is complicated (Rahman et al,2017). Upon arriving to the Holy City of Mecca, the pilgrims are bounded by specific religious obligations and event during the Hajj pilgrimage which required to be completed within specific time limit. As for consequence, in some cases, the huge crowd event had led to fatal accidents among the pilgrims. Fruin (1993) stated that crowd management is understood as a systematic planning for the arranged movement and assembly of members as people. Therefore, the improvement on pedestrian facilities provided is essential to ensure smooth flows of the pilgrim's event and comfort. In fact, providing an excellent service for pilgrims is among the main concern of Saudi's Hajj management (Yamin \& Albugami, 2014). The fact that it is quite challenging to alter the pilgrim's facilities considering the pilgrims health, safety, and security, however, this effort will bring benefit to the future pilgrims.

\section{LITERATURE REVIEW}

\section{Pedestrian movement and traffic condition during Hajj}

Makkah is still expanding, and the Hajj pilgrims is expected to rise up to 5 million according to the vision of 2030 (Saeed et al., 2021). However, due to Covit-19 
pandemic, the Saudi government had announced that there is no Hajj in 2020 until further notice. To handle the pilgrim crowds, the Saudi government has constructed three mobility types that connect the old city of Mecca to the new districts by the current tunnel networks, namely i) vehicle-only, ii) vehicle and pedestrian, as well as, iii) pedestrian-only tunnels. Based on Figure 1, during the Nafrah of pilgrims, the pedestrian's movement and vehicles from Arafat to Muzdalifah experience severe bottlenecks due to huge pilgrim crowd's arrival in Muzdalifah after the dawn of "Fajr". As a result, the Haij pilgrims experience discomfort and stressful condition, as they are required to reach the next destination within stipulated time.

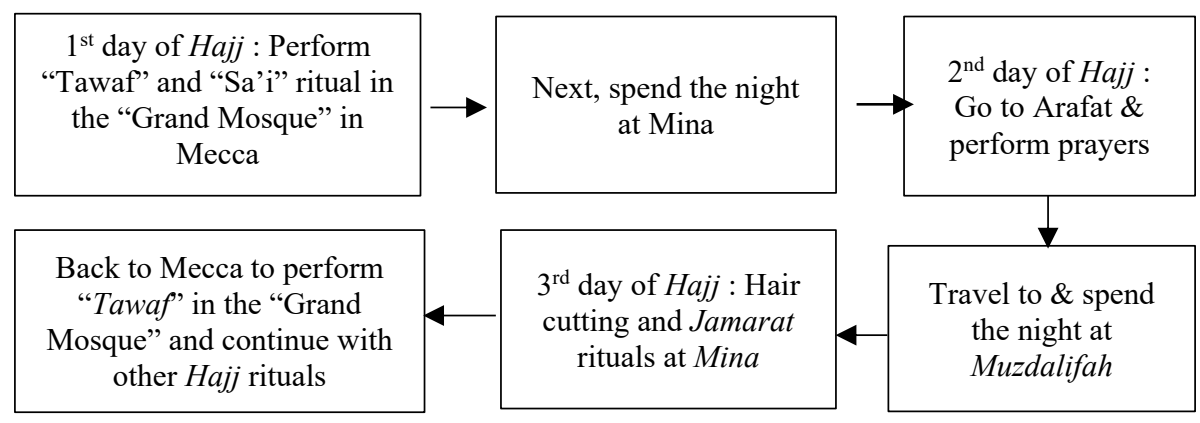

Figure 2: Main Activity of performing Hajj in Mina, Arafat and Muzdalifah Source: Adapted from Yamin \& Albugami (2014)

The Arafat is the most crowded site during the $2^{\text {nd }}$ day of Hajj. Hence, the existing facilities at Hajj areas turn more congested due to overcrowding of pilgrims and causing limited pedestrian movements (Owaidah, et.al (2019). Abdelghany et al. (2012), estimated that the peak pedestrian flow rate between Arafat and Muzdalifah had reached 500,000 pilgrims per hour and expected to increase by years. Friberg \& Hjelm (2015), emphasized that pedestrian overcrowding may lead to rushes, traffic and human bottlenecks, counter flows, stop-and-go waves, crowd turbulence, and panic among the pilgrims. Therefore, the Hajj traffic department had developed traffic plans, to reduce the traffic congestion, including Nafrah from Arafat to Muzdalifah, by constructing expensive corridors along roads for wagons (Alkharoubi, 2020). Unfortunately, this issue still remains until today. The Hajj authorities has specified four roads for pedestrians and five roads for vehicles to reduce the issues of critical pedestrian-vehicles conflict within the Arafat-Muzdalifah Road. During this time, around half a million pedestrians choose to walk to Muzdalifah. At sunset, a massive traffic jams with slow vehicle movement causes some passengers decide to walk for the rest of the distance. 
Sadeq Kadi, Alias Abdullah, Syahriah Bachok

The Evaluation of Pedestrian Facilities on Hajj Crowd Between Arafat and Muzdalifah Pedestrian Street

\section{The significant of pedestrian facilities during Hajj}

Kaya (2009) emphasizes that one of the important approaches to solve the crowd tragedy is to improve the level of services on pedestrian facilities aspect. Moroever, the level of street friendliness, pedestrian safety (Sangeeth \& Lokre, 2019), comfort, attractiveness and accessibility (Quednau, 2018) are strongly influenced by the pedestrian facilities provided at particular areas. Hence, it is important for the Saudi government to consider these aspects, particularly for such important event of Hajj pilgrimage. Indeed, street walkability increases when the street offers comfortable, safe and accessible pedestrian infrastructure to its users, (Litman (2016), Kinyingi, Mugwima \& Karanja, 2020). When the street offers comfortable environment with smooth pedestrian flow and easily accessible street, the pilgrims would have more time to focus on their Hajj activities, without being distracted by other factors such as being lost or anxious while performing Hajj. Additionally, the Hajj crowd had resulted to stress (Alsolami, Embi, \& Enegbuma 2017) and decreased of positive emotion (Kim, Lee, \& Sirgy ,2015), which affect the pilgrims' satisfaction. In this study, it can be suggested that the pedestrian street for Hajj does not necessarily attractive. However, factors such as safety, comfortable and accessible need to be taken seriously, to ensure the Hajj pilgrimages efficiency.

\section{RESEARCH METHODOLOGY}

Qualitative research method of site inventory and analysis were applied to achieve the aim and objectives of this paper. Observation was made based on the prepared site inventory checklist, formulated based on previous literature reviews. Google earth mapping is produced to investigate the existing facilities on one of the walkway roads between Arafat and Muzdalifah (Saunders et al., 2018). The case study focuses on Nafra access roads, from Arafat to Muzdalifah (Figure 4.1). By analyzing the current facilities between Arafat and Muzdalifah, the researchers will have the ability to determine the existing services between the two locations (Langley \& Klag, 2019).

\section{Site inventory and analysis}

Figure 4.1 below demonstrates the selected pedestrian route from Arafah to Muzdalifah which are divided into eleven (11) segments with $400 \mathrm{~m}$ to $500 \mathrm{~m}$ length each (Meenakshi,2011; Garau, Annunziata and Yamu,2020). Each segment was divided based on the comfortable walking range of 5 to 10 minutes walking suggested from numerous walkability study. The assessments look into either the nearest facilities provided are easy to reach or vice versa. Azmi, Karim and Amin (2012), suggested that the accepted threshold for walking to local facilities is within $400 \mathrm{~m}$, while $800 \mathrm{~m}$ is a suggested threshold for walking to a town centre. Hence, in this study, the range of $400 \mathrm{~m}$ to $500 \mathrm{~m}$ were applied for 
walking threshold to the pedestrian facilities provided for selected route of this study.

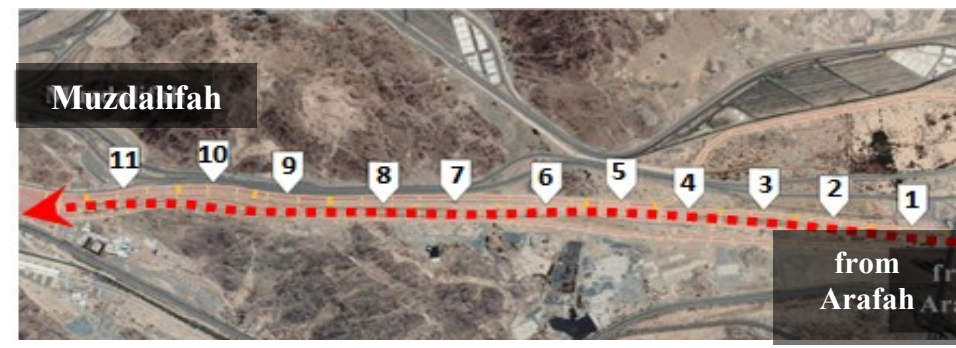

Figure 4.1: The location and key plan for Nafra, from Arafah to Muzdalifah Source: Google Map (2021)

\section{Availability and Access to Pedestrian facilities}

Table 4.1 below presents the findings for each pedestrian facility provided along the selected street from Arafat to Muzdalifah for $400 \mathrm{~m}$ to $500 \mathrm{~m}$ range of walking.

Table 4.1: Findings on pedestrian facilities available at selected pedestrian street

\begin{tabular}{|c|c|c|c|c|c|c|c|c|c|c|}
\hline 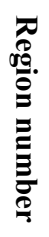 & 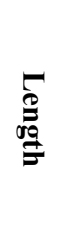 & 豙 & 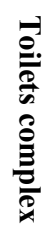 & 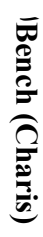 & 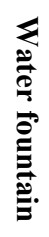 & 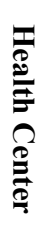 & 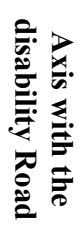 & 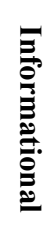 & 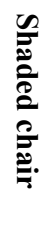 & 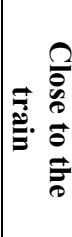 \\
\hline 1 & 400 & 30 & $\sqrt{ }$ & $\sqrt{ }$ & $\sqrt{ }$ & $\sqrt{ }$ & $\mathrm{x}$ & $\sqrt{ }$ & $\mathrm{x}$ & $\mathrm{x}$ \\
\hline 2 & 400 & 30 & $\sqrt{ }$ & $\sqrt{ }$ & $\sqrt{ }$ & $\mathrm{X}$ & $\sqrt{ }$ & $\sqrt{ }$ & $\mathrm{x}$ & $\mathrm{x}$ \\
\hline 3 & 400 & 30 & $\sqrt{ }$ & $\sqrt{ }$ & $\sqrt{ }$ & $\sqrt{ }$ & $\sqrt{ }$ & $\mathrm{x}$ & $\mathrm{x}$ & $\mathrm{x}$ \\
\hline 4 & 400 & 30 & $\sqrt{ }$ & $\sqrt{ }$ & $\sqrt{ }$ & $\mathrm{x}$ & $\sqrt{ }$ & $\sqrt{ }$ & $\mathrm{x}$ & $\mathrm{x}$ \\
\hline 5 & 400 & 52 & $\sqrt{ }$ & $\sqrt{ }$ & $\sqrt{ }$ & $\mathrm{X}$ & $\sqrt{ }$ & $\mathrm{x}$ & $\mathrm{x}$ & $\mathrm{x}$ \\
\hline 6 & 460 & 22 & $\sqrt{ }$ & $\sqrt{ }$ & $\sqrt{ }$ & $\mathrm{x}$ & $\sqrt{ }$ & $\mathrm{x}$ & $\mathrm{x}$ & $\mathrm{x}$ \\
\hline 7 & 450 & 22 & $\sqrt{ }$ & $\sqrt{ }$ & $\sqrt{ }$ & $\sqrt{ }$ & $\sqrt{ }$ & $\sqrt{ }$ & $\sqrt{ }$ & $\mathrm{x}$ \\
\hline 8 & 450 & 22 & $\sqrt{ }$ & $\sqrt{ }$ & $\sqrt{ }$ & $\mathrm{x}$ & $\mathrm{x}$ & $\mathrm{x}$ & $\mathrm{x}$ & $\mathrm{x}$ \\
\hline 9 & 400 & 52 & $\sqrt{ }$ & $\sqrt{ }$ & $\sqrt{ }$ & $\mathrm{x}$ & $\mathrm{x}$ & $\sqrt{ }$ & $\mathrm{x}$ & $\mathrm{x}$ \\
\hline 10 & 400 & 52 & $\mathrm{x}$ & $\sqrt{ }$ & $\sqrt{ }$ & $\mathrm{X}$ & $\mathrm{x}$ & $\mathrm{x}$ & $\mathrm{x}$ & $\mathrm{x}$ \\
\hline 11 & 490 & 52 & $\sqrt{ }$ & $\sqrt{ }$ & $\sqrt{ }$ & $\sqrt{ }$ & $\mathrm{x}$ & $\mathrm{x}$ & $\mathrm{x}$ & $\sqrt{ }$ \\
\hline
\end{tabular}

$* \sqrt{ }$ - available, $\mathrm{x}$ - not available

Sources: Author (2021)

\section{Pedestrian lane}

Table 4.1 evidenced the pedestrian lane width provided along the route were inconsistent where segment one until four were designed with $30 \mathrm{~m}$ in width. Meanwhile, the fifth, and nine to eleventh were designed with $52 \mathrm{~m}$ in width, segment 6 until 8 demonstrated of $22 \mathrm{~m}$ width. The pedestrian lane inconsistent with width because certain segments were merged together. Hence, resulted in 
Sadeq Kadi, Alias Abdullah, Syahriah Bachok

The Evaluation of Pedestrian Facilities on Hajj Crowd Between Arafat and Muzdalifah Pedestrian Street

larger pedestrian lane of 52m width, for instance segment number 5, 9, 10 and 11. Figure 4.2 illustrates the merging of pedestrian segments of number 5 and 9.

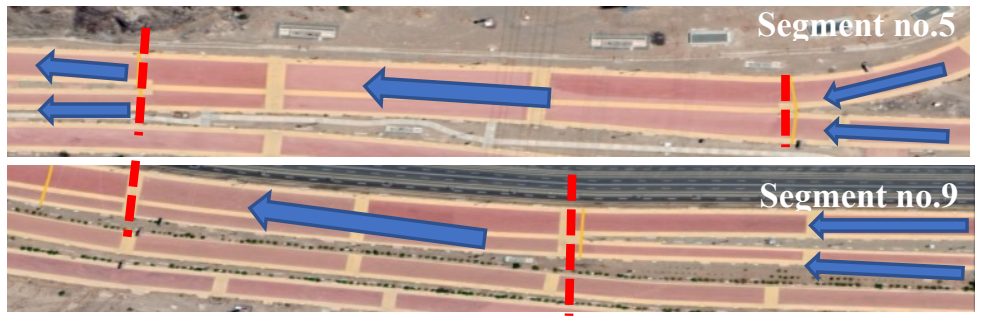

Figure 4.2: The dotted red line illustrate the merging of two sidewalk for segment no. 5 and no.9

Based on the observation, the merging of two separated pedestrian lanes shared the same pedestrian facilities and services which includes benches, water cooler, signage and lighting elements. Hence, it can be suggested that different paving material could be applied for two pedestrian lane segment that merged together to avoid discomfort and conflict among pedestrian. The safety of pilgrim is also uncompromised in Hajj condition as the crowds are rushing to reach the stipulated destination within limited time. Nashar (2018) highlighted that pedestrian comfort is measured through their freedom to change the body directions at any time and to walk freely whenever they feel like it without any conflict. Harun,Nashar and Bachok (2020), emphasis that street walkability is associated with other attributes such as visual quality, attractiveness, safety and comfort. In this context, safety and comfort of pilgrim are two important that need to be taken into consideration. Based on the arguments, the existing pedestrian lane width provided does not provide comfort to the pilgrims (Figure 4.3).
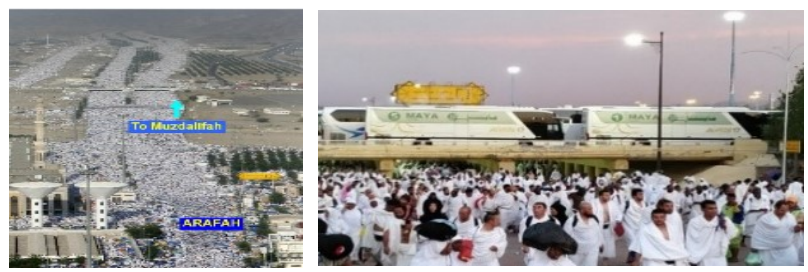

Figure 4.3: Pedestrian crowd along the route from Arafat to Muzdalifah
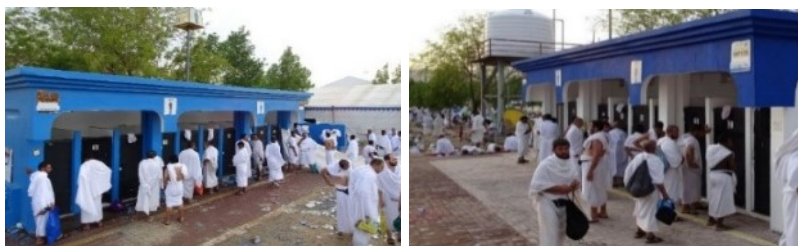

Figure 4.4: Pilgrims wait for their turn to use the toilet provided 
PLANNING MALAYSIA

Journal of the Malaysia Institute of Planners (2021)

\section{Toilet complex}

Table 4.1 evidenced only segment no.10 is not equipped with toilet facilities. However, the observation indicated that more toilets should be added to ease the pilgrims' Hajj journey and to minimize waiting time to use the toilet (Figure 4.4). Walking affordance are varied based on the different group ages and backgrounds. Older people have slower walking pace as compared to the younger group age. In a case of emergency, people with slower walking pace might face discomfort and difficulties. Azmi, Karim, \& Amin (2012), supported that the maximum walking distance for the elderly from Asian countries or are only 190 meters, $191 \mathrm{~m}$ to $380 \mathrm{~m}$ of walking distance for children. Maximum distance for adults is from $381 \mathrm{~m}$ to $600 \mathrm{~m}$. Over 600 meter is considered as uncomfortable distance to walk.

\section{Benches, shaded chair and water fountain}

Based on Table 4.1, the benches and water fountains are available and functional at every segment from Arafah to Muzdalifah. However, shaded chairs are only available at segment no.7. Hence, it can be indicated that the presence of shaded chair is essential, particularly in a country that experience both rainy and hot humid climate (Figure 4.5). In hotter and more humid cities, walking affordance may end up shorter in open and unshaded street. Hence, improving the walking environment by installing overhead canopies or shades can significantly increase the pedestrian comfort and willingness to walk. Indeed, shading elements in any form is essential to offer pedestrian comfort from hot and humid environment or climate (Babu, Subbaiyan \& Tadepalli, 2016), helps to decrease paving heat and temperature including low albedo materials (Kasim et.al, 2019).

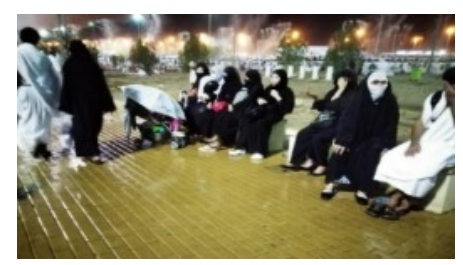

Figure 4.5: Pilgrims are resting under uncovered bench during rainy season

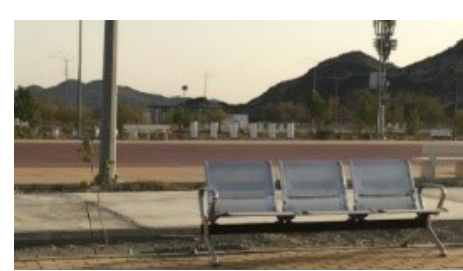

Figure 4.6: Aluminum bench material is unsuitable for hot and humid climate
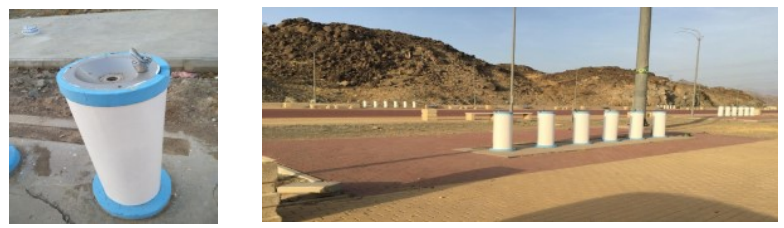

Figure 4.7: Water fountain stop point provided for the use of pilgrims 
Sadeq Kadi, Alias Abdullah, Syahriah Bachok

The Evaluation of Pedestrian Facilities on Hajj Crowd Between Arafat and Muzdalifah Pedestrian Street

In terms of water fountain, each segment has been provided with water cooler station which provides free water for the pilgrims to boost up their energy especially during hot and humid climate.

\section{Healthcare centre, signage and proximity to train station}

The presence of healthcare centre is essential to Hajj journey particularly during an emergency case. According to Table 4.1, few segments provided with the healthcare facilities including segment no.1, no.3., no.7 and no.11. However, the color selection for the healthcare building does not attract the pedestrian eyes and some pilgrims might overlook the healthcare building. To add, the healthcare centre signage font is unreadable from the other pedestrian lane area (Figure 4.8). The information signage on availability of pedestrian facilities and location were provided only at certain checkpoint. Nevertheless, the signage condition of font size and colors are not attractive and readable to the pilgrims (Figure 4.8). Hence, bright and contrast color for signage font can be applied to improve the signage legibility and to make it more visible for the pedestrians. The object with higher contrast, enable pedestrians to read the signage easily (Rapport, 1990). The signage readability is very crucial for those pilgrims that are not familiar with the area. This statement is supported by study conducted by Bohari, Bachok and Osman (2014), that familiarities is one of the important measures to influence the pedestrian walking speed and avoid lost in a particular destination. If the walking speed increase, less walking time is required to reach the destination.
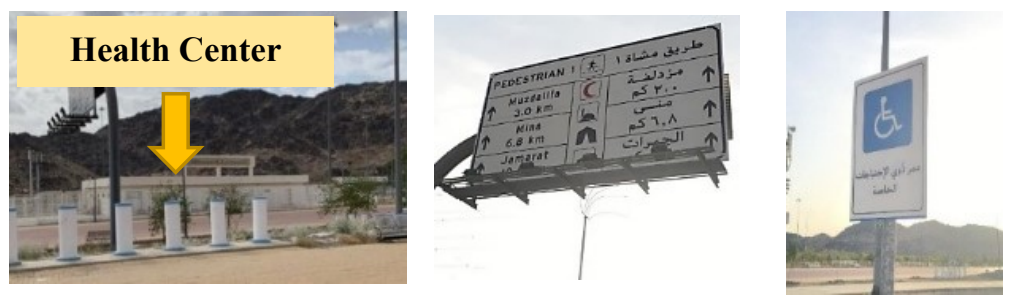

Figure 4.8: Unattractive health centre and signage condition provided at selected segment of pedestrian route

Finally, based on Table 4.1, the results showed that only segment 11 is the nearest checkpoint to the train station, with only $400 \mathrm{~m}$ to $450 \mathrm{~m}$ distance away. Countries that experience hot and humid climate rely more on public transport commuters. Hence, few more checkpoints to the commuters would ease the Hajj journey considering the pedestrian comfort and safety of walking. As majority of pedestrians and public transport commuters depends mainly on walking as primary mode of daily travelling, it is essential for the authority to improve on pedestrian facilities and provide better public transport system. Indeed, other 
studies also suggested that besides safety and accessibility, street infrastructure is one of the important design elements to ensure the pedestrian comfort. In this context the pedestrian refers to the pilgrims who is performing the Hajj.

\section{Conclusion}

In summary, based on the presented findings and analysis, majority of the existing pedestrian facilities provided are insufficient to support the numbers of pilgrims that keep increasing by years, coming from different countries and age groups. Modern facilities for Hajj are adequate for just two million people. On the other hand, since pedestrian walking affordances are vary depending on age and pilgrim's background, this research suggests the common walking radius to access the pedestrian facilities provided. The distance use to conduct the analysis, is by considering pedestrian's comfort, security, and safety for pilgrims during their movement between the holy sites which are Arafat to and from Muzdalifa, as well as to and from Mina) (Haase et al., 2016). It is hoped that the implication from this research would help to improve the existing condition of the busiest routes during Hajj pilgrimages to increase the pedestrian comfort and safety in the near future.

\section{ACKNOWLEDGMENT}

First and foremost, I have to thank my father for his love and support in my life and help me to chase my dreams. This research acknowledge the support from the faculty of Architecture and Environmental Design (KAED), IIUM, Prof. Dato' TPr. Dr. Alias Abdullah, Prof. Dr. Berghout Abdelaziz, Assoc. Prof. TPr. Dr. Syahriah Bachok Additionally, thanks to the custodian of the two holy mosques institute for Hajj and Umrah Research.

\section{REFERENCES}

Abdelghany, A., Abdelghany, K., Mahmassani, H., \& Al-Zahrani, A. (2012). Dynamic simulation assignment model for pedestrian movements in crowded networks. Transportation Research Record, (2316), 95-105. http://dx.doi.org/10.3141/2316-11

Alnabulsi H., Drury J., (2014).Social identification moderates the effect of crowd density on safety at the Hajj. Proceedings of the National Academy of Sciences, 111 (25), 1-6. https://doi.org/10.1073/pnas.1404953111

Al Nabulsi, H. (2015). The crowd psychology of the Hajj. (Doctoral dissertation). University of Sussex, Brighton, United Kingdom.

Alsolami, B. M., Embi, M. R., \& Enegbuma, W. I. (2017). The Influence of Sustainable Physical Factors on Hajj Crowd Perception among Internal Pilgrim Group in Mina. Chemical Engineering Transactions, 56, 409-414. http:// doi/10.3303/CET1756069

Alabdulkarim, L., Alrajhi, W., \& Aloboud, E. (2016). Urban Analytics in Crowd Management in the Context of Hajj. In International Conference on Social Computing and Social Media (pp. 249-257). Springer. http://dx.doi.org/10.1007/978-3-319-39910-2_23 
Sadeq Kadi, Alias Abdullah, Syahriah Bachok

The Evaluation of Pedestrian Facilities on Hajj Crowd Between Arafat and Muzdalifah Pedestrian Street

Alkharoubi, A. (2020). Wayfinding for Pedestrians in the Crowded Areas of Al-Hajj: How Can Wayfinding System Designs Increase the Efficiency of Wayfinding and Navigation Performances for Pedestrian Pilgrims During the Islamic Pilgrimage (AlHajj).(Doctoral Disertation). University of Minnesota, Minneapolis, United States.

Azmi, D. I., Karim, H. A., \& Amin, M. Z. M. (2012). Comparing the walking behaviour between urban and rural residents. Procedia-Social and Behavioral Sciences, 68, 406416. https://doi.org/10.1016/j.sbspro.2012.12.237

Babu, R., Subbaiyan \& Tadepalli S. (2016). Assessing the Needs of Pedestrian Facilities at Tiruchirappalli, India, International Journal of the Malay World and Civilisation (Iman) 4 (2),87 - 90.

Bohari, Z. A., Bachok, S., \& Osman, M. M. (2014). Improving the Quality of Public Transportation System: Application of simulation model for passenger movement. Procedia-Social and Behavioral Sciences, 153, 542-552.

Felemban, E. A., Rehman, F. U., Biabani, S. A. A., Ahmad, A., Naseer, A., Majid, A. R. M. A., \& Zanjir, F. (2020). Digital Revolution for Hajj Crowd Management: A Technology Survey. IEEE Access, 8, 208583-208609.

Friberg, M. \& Hjelm, M. (2015). Mass evacuation-human behaviour and crowd dynamicsWhat do we know?, LUTVDG/TVB, 1-61.

Fruin, J., J.(1993). The causes and prevention of crowd disasters, Engineering for Crowd Safety. Elsevier, 1(10),99-108.

Garau, C., Annunziata, A., \& Yamu, C. (2020). A walkability assessment tool coupling multicriteria analysis and space syntax: The case study of Iglesias, Italy. European Planning Studies, 1-23. https://doi.org/10.1080/09654313.2020.176194

Gifford R., (2007). Environmental psychology: Principles and practice. Optimal books Colville, Washington, US.

Haase, K., Al Abideen, H. Z., Al-Bosta, S., Kasper, M., Koch, M., Müller, S., \& Helbing, D. (2016). Improving pilgrim safety during the hajj: an analytical and operational research approach. Interfaces, 46(1), 74-90. http://dx.doi.org/10.1287/inte.2015.0833

Harun, N. Z., Nashar, A., \& Bachok, S. (2020). Walkability Factors for a Campus Street. Planning Malaysia, 18(11), 45-55.

Kasim, Z., Shahidan, M. F., Ujang, N., \& Dahlan, N. D. (2019). Influence of landscape environmental settings on outdoor pedestrian thermal comfort in tropical climate. Alam Cipta, 12(2), 74-85.

Kaya, D. (2009). Partial differential equations that lead to solitons. In Encyclopedia of Complexity and Systems Science, pp 6453-6459. https://doi.org/10.1007/978-0-38730440-3_380

Kim D., Lee C.K., \& Sirgy M.,J.(2015). Examining the differential impact of human crowding versus spatial crowding on visitor satisfaction at a festival. Journal of Travel and Tourism $\quad 33$ Marketing 293-312. https://doi.org/10.1080/10548408.2015.1024914

Kingshott, B. F. (2014). Crowd management: Understanding attitudes and behaviors. Journal of Applied Security Research, 9(3), 273-289. https://doi.org/10.1080/19361610.2014.913229

Kinyingi, J., Mugwima, N., \& Karanja, D. (2020). Walkable Streets: A Study of Pedestrians ' Perception, and Attitude towards Ngei Street in Machakos Town. Current Urban Studies, 8 (3), 381. https://doi.org/10.4236/cus.2020.83021 
Khalid, N. S., Othman, R. N. R., \& Marzukhi, M. A. (2020). Public Spaces And Gender: Testing The Relationship Of Spatial Configuration Of Street Networks. Planning Malaysia, 18(14).92-133

Langley, A., \& Klag, M. (2019). Being where? Navigating the involvement paradox in qualitative research accounts. Organizational research methods, 22(2), 515-538. https://doi.org/10.1177/1094428117741967

Litman, T. A. (2016). Evaluating Transportation Land Use Impacts: Considering the Impacts, Benefits and Costs of Different Land Use Development Patterns. Transportation Research Board, (1), 1-69.

Meenakshi (2011). Neighbourhood unit and its conceptualization in the contemporary urban context. India Journal,8, 81-87.

Nashar, A. (2018). Streetscape planning guidelines for walkable campus .Master's thesis, International Islamic University Malaysia, Kuala Lumpur.

Owaidah, A., Olaru, D., Bennamoun, M., Sohel, F., \& Khan, N. (2019). Review of modelling and simulating crowds at mass gathering events: Hajj as a case study. Journal of Artificial Societies and Social Simulation, 22(2). https://doi.org/10.18564/jasss.3997

Quednau, R. (2018). Why Walkable Streets Are More Economically Productive . Strong Towns Article.Retrived at https://www.strongtowns.org/journal/2018/1/16/whywalkable-streets-are-more-economically-productive-3bzg5

Rahman, J., Thu, M., Arshad, N., \& Van der Putten, M. (2017). Mass gatherings and public health: case studies from the Hajj to Mecca. Annals of global health, 83(2), 386-393. https://doi.org/10.1016/j.aogh.2016.12.001

Rapoport, A. (1990). The Perceptual Characteristics of Pedestrian Streets. In History and Precedent in Environmental Design (pp. 261-296). Springer,https://doi.org/10.1007/978-1-4613-0571-2_8

Sangeeth, K., \& Lokre, A. (2019). Factors influencing pedestrian speed in level of service (LOS) of pedestrian facilities. Transportation research interdisciplinary perspectives, 3, 100066. https://doi.org/10.1016/j.trip.2019.100066

Saeed, F., Schleussner, C. F., \& Almazroui, M. (2021). From Paris to Makkah: heat stress risks for Muslim pilgrims at $1.5^{\circ} \mathrm{C}$ and $2^{\circ} \mathrm{C}$. Environmental Research Letters, 16(2), 024037.

Saunders, B., Sim, J., Kingstone, T., Baker, S., Waterfield, J., Bartlam, B., Burroughs, H., \& Jinks, C. (2018). Saturation in qualitative research: exploring its conceptualization and operationalization. Quality \& quantity, 52(4), 1893-1907. https://doi.org/10.1007/s11135-017-0574-8

Yamin, M., \& Albugami, M. A. (2014,). An architecture for improving Hajj management. In International Conference on Informatics and Semiotics in Organisations, Springer, 187-196. https://doi.org/10.1007/978-3-642-55355-4_19

Received: $13^{\text {th }}$ July 2021. Accepted: $5^{\text {th }}$ December 2021 